\title{
SIMULATION OF CONCURRENT GAMES
}

\author{
A.N. Ivutin, Tula State University, Tula, Russian Federation, \\ alexey.ivutin@gmail.com, \\ E.V. Larkin, Tula State University, Tula, Russian Federation, elarkin@mail.ru
}

\begin{abstract}
Concurrent games, in which participants run some distance in real physical time, are investigated. Petri-Markov models of paired and multiple competitions are formed. For paired competition formula for density function of time of waiting by winner the moment of completion of distance by loser is obtained. A concept of distributed forfeit, which amount is defined as a share of sum, which the winner gets from the loser in current moment of time is introduced. With use of concepts of distributed forfeit and waiting time the formula for common forfeit, which winner gets from loser, is obtained. The result, received for a paired competition, was spread out onto multiple concurrent games. Evaluation of common wins and loses in multiple concurrent game is presented as a recursive procedure, in which participants complete the distance one after another, and winners, who had finished the distance get forfeits from participants, who still did not finish it. The formula for evaluation of common winning in concurrent game with given composition of participants is obtained. The result is illustrated with numerical example.

Keywords: competition; concurrent game; Petri-Markov net; distance; distributed forfeit; waiting time; common winning; paired competition, multiple competition.
\end{abstract}

\section{Introduction}

At present time the game theory is widely used in economics, industry, military, parallel computing and in other spheres of human activity. Traditionally the game theory was developed as a methodology of forming of strategies in struggle for some resource, and the dynamics of game was interpreted as a correction of strategy during the game without link activity of participants to real physical time [1]. As a matter of fact any competition is developed in real physical space/time. The space aspect lies in necessity of conversion of any resource (material, energetic, informational, etc.) of pre-specified volume by participants. This resource below will be symbolically called "the distance". The space aspect lies in the fact, that a concurrent participant can overcome the distance not instantly, but in finite time. Time of overcoming of distance by a participant is random and individual for every participant.

Time aspects of concurrent game evolution are investigated insufficiently. In particular the problem of evaluation of forfeits, when forfeits are linked to a time factor is not solved.

In this article there were accepted the following restrictions:

1. Concurrent game consists in passing the equal distance by participants, in real physical time: all participants start passing the distance at the same time;

2. The time of passing the distance by any of participant is random and is defined for each participant individually with precision to density of distribution;

3. Winning or losing in competition is understood as finishing the distance and being the first or the second; 
4. The winner doesn't get the forfeit, value of which is distributed in time, until the loser finishes the distance.

Passing the distance by participants may be presented as a parallel random process. For its investigation a mathematical apparatus of Petri-Markov nets [2], which is a development of formalism of Petri nets (both classic and time-extended) [3-6] may be used. The usage the formalism of Petri-Markov nets allows to define a time factor, which stipulates a forfeit from loser to winner, and to evaluate cost parameters of a concurrent game.

\section{Waiting Time at Paired Competition}

Competition of two participants is represented by a Petri-Markov net [2]:

$$
\psi_{2}=\left(\Pi_{2}, M_{2}\right),
$$

where $\Pi_{2}=\left\{A_{2}, Z_{2}, R_{2 A Z}, R_{2 Z A}\right\}$ is a structure of the Petri net; $M_{2}=\left[\boldsymbol{q}_{2}, \boldsymbol{f}_{2}(t), \boldsymbol{L}_{2}\right]$ is a semi-Markov process; $A_{2}=\left\{a_{1}, a_{2}\right\}$ is a set of places; $Z_{2}=\left\{z_{1}, z_{2}\right\}$ is a set of transitions; $R_{2 A Z}=\left(\begin{array}{ll}0 & 1 \\ 0 & 1\end{array}\right)$ is an adjacency matrix, which represents transitions of set of places $A_{2}$ to set of transactions $Z_{2} ; R_{2 Z A}=\left(\begin{array}{ll}1 & 1 \\ 0 & 0\end{array}\right)$ is an adjacency matrix, which represents transitions of set $Z_{2}$ to set of places $A_{2} ; q_{2}$ is a vector, which determines probabilities of start of a process in one of transitions of set $Z_{2} ; f_{2}(t)=\left[\begin{array}{cc}0 & f_{1}(t) \\ 0 & f_{2}(t)\end{array}\right]$ is a matrix of time densities of stay of semi-Markov process stay in places of set $A_{2} ; L_{2}=\left(\begin{array}{ll}1 & 1 \\ 0 & 0\end{array}\right)$ is a matrix of logical conditions for switching the process from the transitions of set $Z_{2}$.

The following restrictions are imposed on time densities: $f_{1,2}(t)=0$, when $t<0$ and $\int_{0}^{\infty} f_{1,2}(t) d t=1$.

Consider the situation, when the first participant finished the distance at a moment $\tau$ and waits, while the second participant finishes. In this case using a Petri-Markov net (1) there can be formed a semi-Markov process, see fig. 1.

State $\alpha_{0}$ simulates the start of semi-Markov process. State $\alpha_{1}$ is the absorbing one and simulates finishing of the distance by the second participant, if the first participant hadn't finished it. State $\alpha_{2}$ is the absorbing one and simulates the end of waiting by the first participant for finishing of the distance by the second participant. The subset of states $\beta$ simulates the process of completion of the distance by the second participant in the case when the first participant had finished it.

Time counting in semi-Markov process, shown on fig. 1.begins when the first participant gets the finish of the distance. Probability of the fact that the first participant completes his distance exactly at time $\tau$ is equal to $f_{1}(\tau) d \tau$. Probability of the fact that second participant does not finish the distance at this time is equal to $1-F_{2}(\tau)$, where $F_{2}(\tau)$ is the distribution function corresponding to time density $f_{2}(t)$. Events of finishing are independent, therefore probability of achievement of subset $\beta$ is equal to $p_{\alpha_{0} \beta}=\int_{0}^{\infty}\left[1-F_{2}(\tau)\right] f_{1}(\tau) d \tau=\int_{0}^{\infty} F_{1}(t) f_{2}(t) d t$. Weighted density of waiting time may 


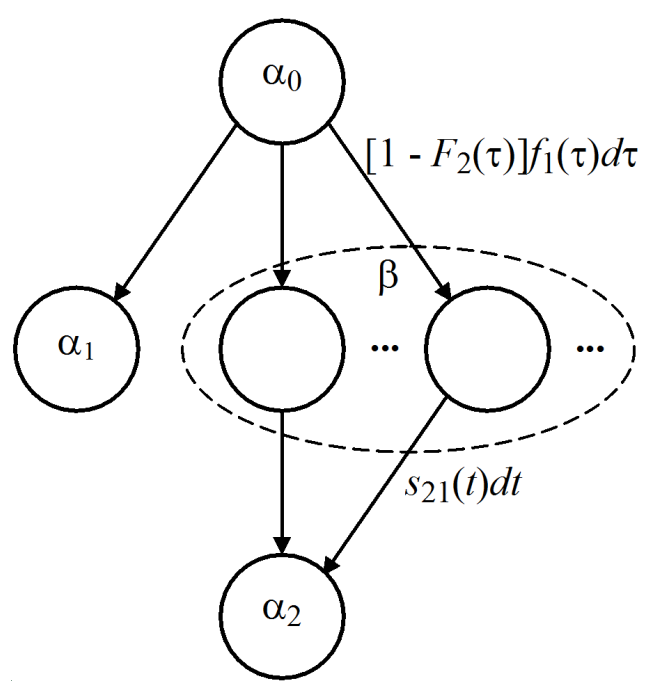

Fig. 1. Waiting time illustration

be received by means of cutting off from correlation integral the meanings with negative argument, $h_{1 \rightarrow 2}(t)=\eta(t) \int_{0}^{\infty} f_{1}(\tau) f_{2}(t+\tau) d \tau$, where $\eta(t)$ is a Heaviside function.

Therefore, the density of waiting time, when the first participant finishes his distance first, is the following

$$
f_{1 \rightarrow 2}(t)=\frac{\eta(t) \int_{0}^{\infty} f_{1}(\tau) f_{2}(t+\tau) d \tau}{\int_{0}^{\infty} F_{1}(t) d F_{2}(t)} .
$$

It is necessary to say, that operation (2) is not the commutative one, and in general case

$$
f_{2 \rightarrow 1}(t)=\frac{\eta(t) \int_{0}^{\infty} f_{2}(\tau) f_{1}(t+\tau) d \tau}{\int_{0}^{\infty} F_{2}(t) d F_{1}(t)} \neq f_{1 \rightarrow 2}(t) .
$$

As an example of waiting time definition consider some significant practical cases.

Case 1 . Time density $f_{1}(t)=\delta\left(t-T_{1}\right)$ is a shifted Dirac $\delta$-function, $f_{2}(t)$ is an arbitrary density function with expectation $T_{2}$ and $T_{2 \text { min }} \leq \arg f_{2}(t) \leq T_{2 \max }$. Expression (2) for this case takes the form

$$
f_{1 \rightarrow 2}(t)=\frac{\eta(t) f_{2}\left(t+T_{1}\right)}{1-F_{2}\left(T_{1}\right)} .
$$

Depending on location of functions $f_{1}(t)$ and $f_{2}(t)$ on time axis, the following situations are possible:

A) $T_{1}<T_{2 \min }$.

In this situation denominator of (4) is equal to 1 and expression (4) transforms to $f_{1 \rightarrow 2}(t)=f_{2}\left(t+T_{1}\right)$. The set of nonzero values of function $f_{1 \rightarrow 2}(t)$ is defined by $T_{2 \min }-T_{1} \leq$ $\arg \left[f_{2}\left(t+T_{1}\right)\right] \leq T_{2 \max }-T_{1}$.

B) $T_{2 \min } \leq T_{1} \leq T_{2 \max }$. 
In this situation waiting time density is defined as (4), and the set of nonzero values of function $f_{1 \rightarrow 2}(t)$ is defined by $0 \leq \arg \left[f_{2}\left(t+T_{1}\right)\right] \leq T_{2 \max }-T_{1}$.

C) $T_{1}>T_{2 \max }$.

In this situation expression (4) is impossible due to the fact, that difference of time intervals completely shifts into area of negative values of argument (the loser cannot wait the winner).

Case 2. Time density is represented by shifted Dirac $\delta$-function, i.e. $f_{2}(t)=\delta\left(t-T_{2}\right)$, $f_{1}(t)$ is an arbitrary time density with expectation $T_{1}$ and $T_{1 \min } \leq \arg f_{1}(t) \leq T_{1 \max }$. Expression (2) for this case takes the form

$$
f_{1 \rightarrow 2}(t)=\frac{\eta(t) f_{1}\left(T_{2}-t\right)}{F_{1}\left(T_{2}\right)} .
$$

Depending on location of functions $f_{1}(t)$ and $f_{2}(t)$ on time axis, the following situations are possible:

A) $T_{2}<T_{1 \min }$.

In this situation expression (5) is impossible.

B) $T_{1 \text { min }} \leq T_{2} \leq T_{1 \text { max }}$.

In this situation waiting time density is equal to (5), and the domain of nonzero values of function $f_{1 \rightarrow 2}(t)$ is defined by to $0 \leq \arg \left[f_{1 \rightarrow 2}(t)\right] \leq T_{2}-T_{1 \min }$.

C) $T_{2}>T_{1 \max }$.

In this situation $f_{1 \rightarrow 2}(t)=f_{1}\left(T_{2}-t\right)$ and $T_{2}-T_{1 \max } \leq \arg \left[f_{1 \rightarrow 2}(t)\right] \leq T_{2}-T_{1 \text { min }}$.

Case 3. Time density $f_{2}(t)$ is represented by an exponential law $f_{2}(t)=\lambda \exp (-\lambda t)$, $f_{1}(t)$ is an arbitrary density function.

Expression (2) for this case takes the form:

$$
f_{1 \rightarrow 2}(t)=\frac{\eta(t) \int_{0}^{\infty} f_{1}(\tau) \lambda \exp [-\lambda(t+\tau)] d \tau}{1-\int_{t=0}^{\infty}[1-\exp (-\lambda t)] d F_{1}(t)}=\lambda \exp (-\lambda t)
$$

It is obvious, that the case under consideration reflects the property of absence of after-effect in pure Markov processes with continual time. Absence of after-effect can be formulated as follows: if time density between two events is distributed by an exponential law, then for external observer time until the next event is distributed by the same law and does not depend on the starting point observation. In our case time density $f_{1}(t)$ simulates an external observer, who is involved into "competition" with Markov process. Independently of events before observation, new time counting begins at the moment of starting of observation.

\section{Evaluation of Effectiveness of a Paired Competition}

One of the most important factors of competition simulation is evaluation of its effectiveness. The natural model of evaluation of effectiveness is a model, in which the participant, who had finished, received the forfeit from a loser. Owing to the fact that competition in a considered case is developing in time and there is a valuation of waiting time (2), the forfeit is defined as a distributed payment $s_{12}(t)$, received by the winner 
(participant 1) from the loser (participant 2) in time $t$. In total the first participant gets from the second participant forfeit which is defined by integral

$$
s_{12}^{+}=\int_{0}^{\infty} f_{1 \rightarrow 2}(t) \cdot s_{12}(t) d t .
$$

If the second participant wins, the first participant pays the forfeit

$$
s_{21}^{+}=\int_{0}^{\infty} f_{2 \rightarrow 1}(t) \cdot s_{21}(t) d t
$$

where $s_{21}(t)$ is the payment, received by the winner (participant 2) from the loser (participant 1) in time $t$.

Generally $s_{12}(t) \neq s_{21}(t), f_{1 \rightarrow 2}(t) \neq f_{2 \rightarrow 1}(t)$, so $s_{12}^{+} \neq s_{21}^{+}$.

\section{Individual Competition of $\boldsymbol{J}$ Participants}

Competition is defined with Petri-Markov net

$$
\begin{aligned}
& \psi_{J}=\left(\Pi_{J}, M_{J}\right), \\
& \Pi_{J}=\left\{\left\{a_{1}, \ldots, a_{j}, \ldots, a_{J}\right\},\left\{z_{1}, z_{2}\right\},\left[\begin{array}{cc}
0 & 1 \\
\ldots \\
0 & 1 \\
\ldots & 1
\end{array}\right],\left[\begin{array}{ccccc}
1 & & 1 & & 1 \\
0 & \cdots & 0 & \ldots & 0
\end{array}\right]\right\} \\
& M_{J}=\left\{(1,0),\left[\begin{array}{ll}
0 & f_{1}(t) \\
& \cdots \\
0 & f_{j}(t) \\
& \cdots \\
0 & f_{J}(t)
\end{array}\right],\left[\begin{array}{ccccc}
1 & & 1 & & 1 \\
0 & \cdots & 0 & \cdots & 0
\end{array}\right]\right\}
\end{aligned}
$$

where $\left\{a_{1}, \ldots, a_{j}, \ldots, a_{J}\right\}$ is a set of places; $\left\{z_{1}, z_{2}\right\}$ is a set of transitions; $f_{j}(t)$ is the time density of distance completion by participant $j, 1 \leq j \leq J$.

If all $J$ participants start the distance simultaneously, then the probability that the $j$-th participant wins is determined as

$$
p_{w j}=\int_{0}^{\infty} f_{j}(t) \cdot \prod_{\substack{k=1 \\ k \neq j}}^{J}\left[1-F_{k}(t)\right] d t
$$

Time density function of finishing by $j$-th participant-winner is determined as

$$
f_{w j}(t)=\frac{f_{j}(t) \cdot \prod_{k=1}^{J}\left[1-F_{k}(t)\right]}{k \neq j} p_{w j} .
$$


In a specific case, when $f_{j}(t)=\lambda_{j} \exp \left[-\lambda_{j} t\right], 1 \leq j \leq J$, we get

$$
p_{w j}=\frac{\lambda_{j}}{\sum_{j=1}^{J} \lambda_{j}} ; f_{w j}(t)=\sum_{j=1}^{J} \lambda_{j} \cdot \exp \left(-t \cdot \sum_{j=1}^{J} \lambda_{j}\right) .
$$

Let us note, that (11), (12) describe conditional time density of winning of participant $j$, when all other participants lose competition. Therefore the conditional time densities of achievement of transition $z_{2}$ for all $J$ participants are equal, and the probabilities are quite different for different participants.

Time density function and probability of taking the last place in competition is determined as

$$
\begin{gathered}
f_{j}(t) \cdot \prod_{k=1}^{J} F_{k}(t) \\
f_{\bar{w} j}(t)=\frac{p_{\bar{w} j(a)} \neq j}{p_{\bar{w} j}=\int_{0}^{\infty} f_{j}(t) \cdot \prod_{\substack{k=1 \\
k \neq j}}^{J} F_{k}(t) d t .} ;
\end{gathered}
$$

Consider the case, when the fact of completion by any $1 \leq K \leq J$ participants from $J$ is important. Let us construct the set $N_{J}$ of $J$-digit binary natural codes and assign the $j$-th binary digit $\sigma_{j}$ to the $j$-th participant. Digit $\sigma_{j}$ may take two values:

$$
\sigma_{j}=\left\{\begin{array}{l}
0, \text { when participant } j \text { finish the distance; } \\
1, \text { when participant } j \text { does not finish the distance. }
\end{array}\right.
$$

Let us select from the set $N_{J}$ the subset $N_{J}^{K} \subset N_{J}$ of binary $J$-digit codes, which have $K$ units and $J-K$ zeros

$$
N_{J}^{K}=\left\{n_{1}, \ldots, n_{c(J, K)}, \ldots, n_{C(J, K)}\right\},
$$

where $C[J, K]=\frac{J !}{K ! \cdot(J-K) !}$ is quantity of $J$-digit codes with $K$ units, which is equal to $K$-th binomial coefficient; $C(J, K)$ is the ordinal number of a code in set (16);

$$
n_{c(J, K)}=\left\langle\sigma_{1}^{c(J, K)}, \ldots, \sigma_{j}^{c(J, K)}, \ldots, \sigma_{J}^{c(J, K)}\right\rangle .
$$

Define a function $\Phi\left(f_{j}, \sigma_{j}^{c(J, K)}\right)$, which takes two values:

$$
\Phi\left(f_{j}, \sigma_{j}^{c(J, K)}\right)=\left\{\begin{array}{l}
F_{j}(t), \text { when } \sigma_{j}^{c(J, K)}=1 ; \\
{\left[1-F_{j}(t)\right] \text {, when } \sigma_{j}^{c(J, K)}=0 .}
\end{array}\right.
$$

Taking into account (18) we get the dependence for time distribution of completion of competition by any $K$ participants from $J$ :

$$
F_{J}^{K}(t)=\sum_{c(J, K)=1}^{C(J, K)} \prod_{j=1}^{J} \Phi\left(f_{j}, \sigma_{j}^{c(J, K)}\right) .
$$


The first derivative of (19) the considered gives time density

$$
f_{J}^{K}(t)=\frac{d \sum_{c(J, K)=1}^{C(J, K)} \prod_{j=1}^{J} \Phi\left(f_{j}, \sigma_{j}^{c(J, K)}\right)}{d t} .
$$

It is obvious, that (20) is the time density (but not weighed density) due to the fact, that after finishing the distance by $K$ participants, the number of participants, who finishes the distance should only increase. Since multiple participation in the competition is impossible.

\section{Evaluation of Effectiveness of Individual Competition}

In this case it is natural to determine forfeits as a payment matrix of size $J \times J$ :

$$
s(t)=\left[s_{i j}(t)\right] .
$$

where $s_{i j}(t)$ is the distribution of forfeit, which in time $t$ the winner (participant $i$ ) receives from the loser (participant $j$ ).

Generally $s_{i j}(t) \neq s_{j i}(t)$, therefore matrix (21) is asymmetrical. Due to the fact, that winner can't forfeit himself, $s_{i i}(t)=0$.

In waiting time participant $i$ wins from participant $j$ a forfeit with total value equal to

$$
s_{i j}^{+}=\int_{0}^{\infty} f_{i \rightarrow j}(t) \cdot s_{i j}(t) d t
$$

where $f_{i \rightarrow j}(t)$ is evaluated by expression (2).

Total forfeit, which the participant can get in the competition, depends on the sequence of completion of distance with use of recursive procedure.

Without loss of generality, we consider the situation when the places in competition are aligned increasing order of indices $j$. In accordance with accepted order on the first step the first participant leaves the competition as a winner. He gets from every participant, who stays on the distance, the forfeit with value equal to

$$
s_{1_{1} j_{1}}^{+}=\int_{0}^{\infty} f_{1_{1} \rightarrow j_{1}}(t) \cdot s_{1 j}(t) d t, 2 \leq j_{1} \leq J
$$

where $j_{1}$ is an index, corresponding to the first step of recursion.

The total prize of the first participant as a winner after first step is equal to the sum of forfeits obtained from participants with numbers from the second to $J$-th:

$$
s_{1 \Sigma}^{+}=\sum_{j_{1}=2}^{J} s_{1_{1} j_{1}}^{+} .
$$

After the first participant completed the competition participants from the second to the $J$-th stay in a concurrent game. Time densities of completion of distance by the rest $[J(a)-1]$ participants are defined by

$$
f_{j_{2}}(t)=f_{1_{1} \rightarrow j_{1}}(t), 2 \leq j_{1} \leq J .
$$


In general the $i$-th participant $i(a)$ wins from participants with number from $(i+1)$-th to $J$-th, forfeits with values equal to

$$
s_{i_{i} j_{i}}^{+}=\int_{0}^{\infty} f_{i_{i} \rightarrow j_{i}}(t) \cdot s_{i j}(t) d t, i+1 \leq j_{i} \leq J .
$$

Total value of winning of the $i$-th participant after the $i$-th stage is equal to the sum of forfeits, obtained from participants with numbers from the $(i+1)$-th to the $J$-th:

$$
s_{i \Sigma}^{+}=\sum_{j_{i}=i+1}^{J} s_{i_{i} j_{i}}^{+}
$$

Time densities of completion of competition by the rest $J-i-1$ participants are defined by

$$
f_{j_{i+1}}(t)=f_{i_{i} \rightarrow j_{i}}(t), i+1 \leq j_{i} \leq J
$$

And finally, after completion of the distance by the $(J-1)$-th participant, the forfeit obtained from the $J$-th participant is equal to

$$
s_{(J-1)_{J-1} J_{J-1}}^{+}=s_{(J-1)_{J-1} \Sigma}^{+}=\int_{0}^{\infty} f_{(J-1)_{J-1} \rightarrow J_{J-1}}(t) \cdot s_{(J-1) J}(t) d t .
$$

Time density of completion of competition by $J$-th participant is equal to

$$
f_{J_{J}}(t)=f_{(J-1)_{J-1} \rightarrow J_{J-1}}(t) .
$$

In addition to winning forfeits from participants, that stay in competition, participants lose forfeits to those, who completed competition earlier. Total losses of the $j$-th participant consist of winnings of participants with numbers from 1 to $j-1$

$$
s_{j \Sigma}^{-}=\sum_{i=1}^{j-1} s_{i_{i} j_{i}}^{+}
$$

In such a way, effectiveness of competition for the $j$-th participant is equal to

$$
s_{j \Sigma}=s_{j \Sigma}^{+}-s_{j \Sigma}^{-} .
$$

It is necessary to say, that probability of announced above order of completion of distance (increment of indexes $j$ ) is equal to

$$
P(j=1,2, \ldots, J)=\prod_{i=1}^{J-1} \int_{0}^{\infty} f_{i_{i}}(t) \prod_{j_{n}=(i+1)_{n}}^{J}\left[1-F_{j_{n}}(t)\right] d t .
$$

Let us evaluate effectiveness of the participant with number one taking part in competition with given composition of participants. The mentioned participant can take any place from the first till the $J$-th. If the first participant takes the $k$-th place $(1 \leq k \leq J)$, then quantity of commutations of participants with numbers $1 \leq j \leq$ $J, j \neq k$, is equal to $M(j=k)=(J-1)$ !. Designate the number of commutation by 
$m(j=k), 1(j=k) \leq m(j=k) \leq M(j=k)$. Then the average winning of the first participant is equal to

$$
\hat{s}_{1}=\sum_{j=1}^{J} \sum_{m(j=k)}^{M(j=k)} s_{1, m(j=k) \Sigma} P_{1, m(j=k) \Sigma},
$$

where $j$ is the ordinal number of the place, hypothetically taken by the first participant; $m(j=k)$ is the ordinal number of the commutation of indexes of participants with numbers from 2 to $J ; s_{1, m(j=k) \Sigma}$ is the total winning of the first participant, who takes the $j$ th place, if places of other participants are distributed in accordance with $m(j=k)$-th commutation; $P_{1, m(j=k) \Sigma}$ is the probability of emergence of the $m(j=k)$-th commutation.

It is obvious that all cases of commutations of places in competition form complete group of incompatible events, thus $\sum_{j=1}^{J} \sum_{m(j=k)}^{M(j=k)} P_{1, m(j=k) \Sigma}=1$.

\section{Numerical Example}

As an example let us consider the case of paired competition, which is described by a Petri-Markov net (1). Time densities $f_{1}(t)$ and $f_{2}(t)$ are equal to (fig. 5a):

$$
f_{1}(t)=\left\{\begin{array}{l}
0, \text { when } 0 \leq t<0,5 \\
e_{1}, \text { when } 0,5 \leq t \leq 1,5 ; \quad f_{2}(t)=e_{1} \exp \left(-e_{2} \cdot t\right) \\
0, \text { when } t>1,5
\end{array}\right.
$$

where parameters $e_{1}$ and $e_{2}$ have the dimensions $\left[\frac{\text { prob. }}{\text { time }}\right]$ and $\left[\frac{1}{\text { time }}\right]$ respectively.

It is obvious that $f_{1}(t)$ and $f_{2}(t)$ have dimension $\left[\frac{\text { prob. }}{\text { time }}\right]$. Expectations of time densities are quite equal, i.e. $T_{1}=T_{2}=1$ [time]. Distribution functions, corresponding to time densities $f_{1}(t)$ and $f_{2}(t)$, and having dimension [prob.] are as follows (fig. $5 \mathrm{~b}$ ):

$$
\begin{aligned}
F_{1}(t)=\left\{\begin{array}{l}
0, \text { when } 0 \leq t<0,5 ; \\
t-0,6, \text { when } 0,5 \leq t \leq 1,5 ; \quad \text { [prob. }] \\
1, \text { when } t>1,5 .
\end{array}\right. \\
\\
\quad F_{2}(t)=1-\exp (-t)[\text { prob.]. }
\end{aligned}
$$

In spite of equality of expectations of $f_{1}(t)$ and $f_{2}(t)$, the probabilities of winning of participants are quite different: $p_{w 1}=0,3834$ [prob.]; $p_{w 2}=0,6166$ [prob.].

Waiting time densities are equal to (fig. 5 c):

$$
\begin{gathered}
f_{1 \rightarrow 2}(t)=e_{1} \exp \left(-e_{2} \cdot t\right)\left[\frac{\text { prob. }}{\text { time }}\right] ; \\
f_{2 \rightarrow 1}(t)=\frac{1}{0,3834}\left\{\begin{array}{l}
0,3834 \cdot \exp \left(e_{2} \cdot t\right) \text { при } 0 \leq t \leq 0,5 ; \\
1-0,2231 \cdot \exp \left(e_{2} \cdot t\right) \text { при } 0,5<t \leq 1,5 .
\end{array} \quad\left[\frac{\text { prob. }}{\text { time }}\right] .\right.
\end{gathered}
$$

If densities of forfeit are equal to

$$
s_{12}(t)=s_{21}(t)=\tilde{N} \cdot \exp (-c t)
$$



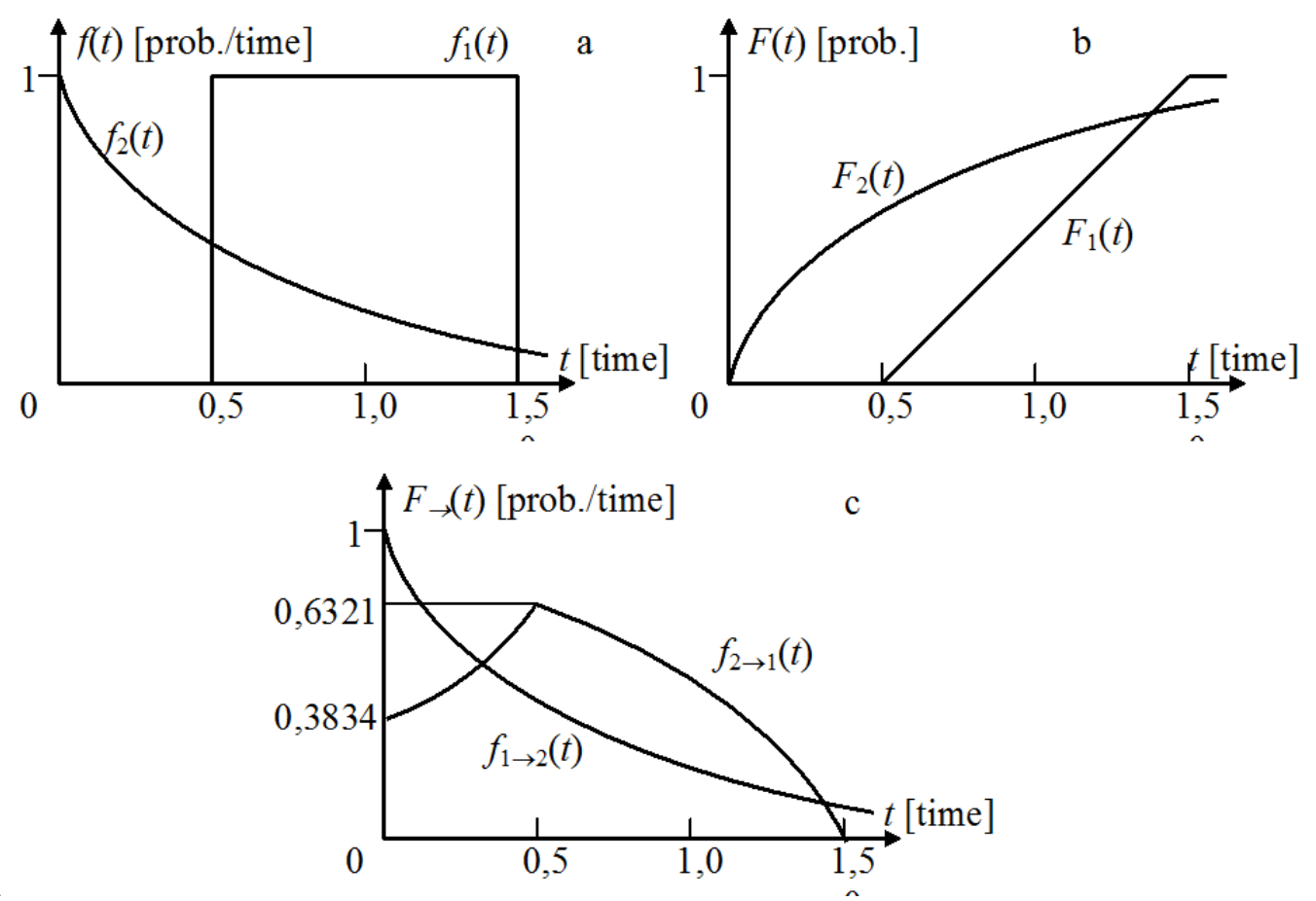

Fig. 2. Time densities and time distributions

where $C\left[\frac{\text { doll. }}{\text { time.prob. }}\right]$ is a coefficient; $c\left[\frac{1}{\text { time }}\right]$ is the rate of diminution of forfeit, then the sum of forfeit received by the first participant from the second one with probability 0,6166 , is equal to

$$
\left.s_{1}^{+}=Q \cdot e_{1} \int_{0}^{\infty} \exp \left[-\left(e_{2}+q\right) \cdot t\right] d t=\frac{Q \cdot e_{1}}{e_{2}+q} \text { [doll. }\right] .
$$

The sum of forfeit, received by the second participant from the first one with probability 0,3834 , is equal to

$$
\begin{gathered}
s_{2}^{+}=\frac{Q}{e_{2}+q}\left[1+1,5819 \cdot \exp 0,5\left(e_{2}-q\right)-0,5819 \cdot \exp 1,5\left(e_{2}-q\right)\right]+ \\
+\frac{2,6082 \cdot Q}{q}(\exp 0,5 q-\exp 1,5 q) .
\end{gathered}
$$

In spite of equality of expectations $f_{1}(t)$ and $f_{2}(t)$, and equality of forfeit densities, sums, that participants can potentially win and probabilities of winning are quite different, and this obstacles should be taken into account when planning concurrent games.

\section{Conclusion}

We have presented a concurrent game as a process of passing the distance by participants in accidental time, which is defined with accuracy to distribution density. Use of mathematical apparatus of Petri-Markov nets allows to determine winner's waiting for other participants time. It also allows to evaluate total forfeits, which losers pay to winner in the case when forfeit density is assigned. Moreover waiting time allows to analyze multiple competition and to evaluate a total participant's winning for known composition of participants. 
Time and stochastic characteristics were obtained in a general form. They are essential for planning the strategy and tactics of concurrent game if strategy/tactics change time densities of distance passed by participants. Next researches in this area may be directed to working out of the apparatus, which links a proposed method of competition simulation with traditional game theory. Moreover the method may be useful for solving the problem of game optimization since it permits to generate a criterion function or restrictions for this problem. Development of this method may be directed to working out of a simple engineering method of effectiveness calculation with use of only numerical characteristics of time distributions.

\title{
References
}

1. Von Neumann J., Morgenstern O. Theory of Games and Economic Behavior. Princeton, N.Y., Princeton University Press, 2007.

2. Ivutin A.N., Larkin E.V., Lutskov Y.I., Novikov A.S. Simulation of Concurrent Process with Petri-Markov Nets. Life Sci J., 2014, vol. 11, pp. 506-511.

3. Petri C.A. Nets, Time and Space. Theor. Comput. Sci., 1996, vol. 153, no. 1-2, pp. 3-48. DOI: $10.1016 / 0304-3975(95) 00116-6$

4. Reisig W. Petri Nets and Algebraic Specifications. Theor. Comput. Sci., 1991, vol. 80, no. 1, pp. 1-34. DOI: 10.1016/0304-3975(91)90203-E

5. Jensen K. Coloured Petri Nets: Basic Concepts, Analysis Methods and Practical Use: Vol. 1. London, Springer-Verlag, 1996. DOI: 10.1007/978-3-662-03241-1

6. Ramaswamy S., Valavanis K.P. Hierarchical Time-Extended Petri Nets (H- EPN) Based Error Identification and Recovery for Hierarchical System. IEEE Trans. on Systems, Man, and Cybernetics- Part B: Cybernetics, 1996, vol. 26, no. 1, pp. 164-175. DOI: 10.1109/3477.484450

\section{МАТЕМАТИЧЕСКОЕ МОДЕЛИРОВАНИЕ СОРЕВНОВАТЕЛЬНЫХ ИГР}

\author{
А.Н. Ивутин, Е.В. Ларкин
}

Исследуются соревновательные игры, заключающиеся в прохождении партнерами некоторой дистанции в реальном физическом времени. Сформированы ПетриМарковские модели парных и множественных соревнований. Для парного соревнования получено выражение для плотности распределения времени ожидания победителем завершения дистанции проигравшим участником. Введено понятие распределенного штрафа, величина которого определяется как доля суммы, которую в текущий 
момент времени получает победитель от побежденного. С использованием понятий распределенного штрафа и времени ожидания получено выражение для суммарного штрафа, который победитель получает от побежденного. Результат, полученный для парных «соревнований», распространен на множественные соревновательные игры. Оценка суммарного выигрыша и проигрыша в множественных соревнованиях представлена в виде рекурсивной процедуры, в которой участники заканчивают дистанцию один за другим, и победители, уже закончившие дистанцию, получают штрафы от участников, еще не закончивших ее. Получено выражение для оценки суммы выигрыша в соревновательной игре с определенным составом участников. Результаты иллюстрируются численным примером.

Ключевые слова: соревнование; соревновательная игра; сеть Петри-Маркова; дистанция; распределенный штраф; время ожидания; суммарный выигрыш; парное соревнование; множественное соревнование.

Алексей Николаевич Ивутин, кандидат технических наук, доцент, кафедра «Вычислительная техника», Тульский государственный университет (г. Тула, Российская Федерация), alexey.ivutin@gmail.com.

Евгений Васильевич Ларкин, доктор технических наук, профессор, кафедра «Робототехника и автоматизация производства», Тульский государственный университет (г. Тула, Российская Федерация), elarkin@mail.ru.

Поступила в редакиию 11 февраля 2015 г. 